\title{
PRAGMÁTICA, HERMENÉUTICA Y NOOLOGÍA. PUGNA DE ANALÍTICAS MÁS ALLÁ DE LA CRIPTOMETAFÍSICA
}

\author{
Jesús CONILL \\ Universidad de Valencia
}

\begin{abstract}
Quiero comenzar agradeciendo al profesor Quintín Racionero la amabilidad de invitarme a participar en esta reflexión conjunta, en la que vamos a intentar entre todos hacer un balance de la filosofía del siglo XX. Espero que esta meditación sirva para orientarnos hacia un futuro en el que podamos ir venciendo la sentida crisis que padece nuestra vida intelectual y, de modo especial, la de carácter filosófico.
\end{abstract}

Un síntoma de esta crisis - que algunos han sabido aprovechar comercialmente bastante bien - son los reiterados entierros y funerales a que nos tienen acostumbrados quienes han decretado que la filosofia ha muerto, siguiendo la moda de ciertas tendencias necrófilas contemporáneas. Otros, en cambio, interpretan su innegable crisis como una enfermedad o un estancamiento, debido a diversas causas, pero fundamentalmente a que casi nadie promueve nuevas ideas filosóficas ni mucho menos nuevos sistemas filosóficos, dado que casi todos se dedican a enseñar o comentar ideas ajenas o a divertirse frívolamente con meros juegos académicos. Este aletargamiento habría conducido a un panorama "desolador" de la filosofía, poblado por una casta de rescolásticos sin escuela» ${ }^{1}$.

Ciertamente desde hace ya más de un siglo se percibe una peculiar crisis de la filosofía, sobre cuyas causas conviene reflexionar, pero atendiendo no sólo a las más directamente endógenas, propias del proceder de las diversas disciplinas

1 M. BUNGE, "Crisis y reconstrucción de la filosofía», en Debats, n. $64-65$ (1999, invierno/primavera), pág. 8-19. 
filosóficas, sino también a las que sirven de caldo de cultivo de éstas. Como nos recuerda Laín Entralgo ${ }^{2}$, prolongando la visión orteguiana, las crisis históricas se producen por el advenimiento de cambios profundos en las ideas y sobre todo en las creencias que configuran un determinado mundo, porque son ellas en lo que se está y con lo que se cuenta para llevar adelante la propia vida (también la intelectual). Sólo así, recuperando el propio "horizonte», podrá proponerse un auténtico programa revitalizador, consistente en una «reconstrucción» o una "transformación» de la filosofia que, a mi juicio, ha de contar con las aportaciones de la pragmática, la hermenéutica y la noología en un tiempo muy proclive a la criptometafísica.

\section{Nuestro horizonte}

Ya a finales del siglo pasado, en nuestro 98, se experienció la crisis del mundo moderno, la pérdida de vitalidad de aquel conjunto de ideas y creencias que dio origen al mundo moderno. Se sintieron las no siempre benéficas consecuencias del principio de la autonomía moderna y de su modelo prevalente de racionalidad, especialmente a través del galopante progreso científico. Las contradicciones y sinsabores que produjo la vivencia de la crisis condujeron a un sentimiento de desilusión y desesperanza.

Precisamente el carácter literario de los representantes de la Generación del 98 constituye, a mi juicio, una peculiar - ahora resulta que pionera - "filosofia literariai ${ }^{3}$, ya que en ella encontramos una forma de aproximación vital a los más diversos asuntos, por la que se logró en España una "reapropiación" de la vida intelectual.

Tal vez esta forma literaria de recuperar la vida intelectual en la España de la Generación del 98 estuviera motivada en gran parte por la situación en que se encontraba entonces la filosofía europea, en la que había hecho mella la "desesperación de la razón en forma de «irracionalismo". Éste puede entederse como una salida del estrechamiento de la razón bajo la influencia del positivismo. Se

2 P. Laín Entralgo, Esperanza en tiempo de crisis, Barcelona, Círculo de Lectores/Galaxia Gutenberg, 1993.

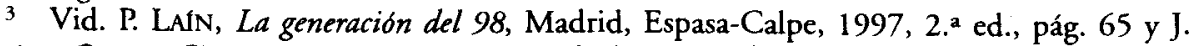
Marlas, Ortega. Circunstancia y vocación I, Madrid, Revista de Occidente, 1973, pág. 74. 
produjo así un giro innovador en la filosofía: de la razón a la vida. Pues lo decisivo es que pensadores como Kierkegaard, Nietzsche, Bergson, Spengler, Unamuno y Machado no dejaron que la razón suplantara la experiencia de la vida y de la historia.

Como espléndidamente nos recuerda Laín, «a fines del siglo XIX es sustituida la antigua fe de los hombres en su razón por una entusiasta afirmación de la vida portadora de esa razón humana, una vida que en modo alguno podría ser reducida a razones (sólo en el siglo XX se intentará el penoso esfuerzo de dar expresión a las posibles "razones» de la "vida»)» 4 .

Ya entonces nuestros pensadores del 98 se apercibieron de las insuficiencias del cientificismo, al que habían estado sometidas las mentes de generaciones anteriores, y se abrieron al nuevo espíritu de la época, para el que, como expresa Laín: "La vida es superior e irreductible a la razón, el sentimiento superior a la lógica, la sinceridad más valiosa que la consecuencia" 5 . Porque lo que realmente importa es "la actividad no racional de la vida humana - pasión, voluntad, sentimiento, sensibilidad, inefable emoción". En Unamuno, Baroja, Azorín, Machado, Ganivet, Valle-Inclán, en todos ellos, se expresa el antagonismo irreductible entre la razón y el corazón, aun cuando también a veces aparece una posible - misteriosa - concordia entre ellos.

Todo esto ha provocado un intento de reforma profunda de la razón antes de derrumbarla o arrumbarla definitivamente. A mi juicio, ha sido ésta una de las aportaciones del pensamiento español a la filosofia contemporánea. No obstante, esta línea filosófica tiene precedentes muy cualificados en la tradición moderna. Recordemos a Pascal, quien, a pesar de tener un gran talento científico, fue un hombre del pathos, de la experiencia, del dolor. Ya a juicio de Pascal, la sola razón no basta. Existe un sentir inmediato, una especie de instinto. Junto al razonamiento ("raisonnement»), también somos capaces de sentimiento, al que aludimos en ocasiones con el término "corazón" ("coeun»). Con tal término aludimos al centro espiritual de la persona humana. Cabe preguntarse entonces si se trata de una "razón de la sinrazón" ${ }^{6} 0$, más bien, de

4 P. LAIN, La Generación del 98, pág. 149.

5 Ibid., 150.

6 P. GARRAGORRI, La filosofia española en el siglo XX, Madrid, Alianza, 1985. 
«razones del corazón». Pues parece ser que «el corazón tiene sus razones que la razón no conoce» ${ }^{7}$.

La repercusión de esta tradición filosófica ha sido muy considerable. $Y$ en esta línea es muy significativo que Zubiri haya entendido la noción pascaliana de "corazón» en los siguientes términos: «no significa el ciego sentimiento, por oposición a la pura razón cartesiana, sino el conocimiento constitutivo del ser cotidiano y radical del hombre» ${ }^{8}$. Con resonancias bíblicas, el corazón tiene que ver con el intelecto, la voluntad y la intención, al igual que con el sentimiento.

La filosofía del siglo XX consiste en gran parte, a mi juicio, en el intento de superar la situación creada por los irracionalismos. Ortega mismo se dedicó a elevar la vida intelectual española a un nivel teórico y a incorporar el vitalismo a una nueva versión de la razón; y ésta fue una de sus aportaciones al legado de la Generación del 98. Inspirado en Nietzsche -aunque saliendo de su "zona tórrida" - Ortega fue capaz de establecer una intrínseca y fecunda relación entre razón y vida.

A mi juicio, este intento de establecer una relación radical entre razón y vida es una de las aportaciones del pensamiento español a la filosofía del siglo $\mathrm{XX}$, contribuyendo a transformar el denominado "método physikôs" (frente al "logikôs»). Ya Unamuno escribió: "Aspiro a la fusión del pensar y del sentir: a pensar el sentimiento y a sentir el pensamiento" ' 9 . Y Ortega comentó en alguna ocasión que quizá el destino nos tenía reservado «unir las dos hermanas enemigas: la pasión y la filosofía, la sensación y la vidan; pues era su propósito sumar "la transparencia de la idea y el estremecimiento de la víscera" ${ }^{10}$.

Esta tradición hispana, desde la "Generación del 98", con Ortega, Zubiri y Zambrano, hasta Laín Entralgo y Marías, ofrece nuevos modos de entender la razón en forma de "razón vital", "razón histórica», "razón poética», "razón sentiente", "corporal" y «esperanzada". Lo cual supone haber descubierto un

7 Pascal, Pensamientos, 277. «Conocemos la verdad no solamente por la razón, sino también por el corazón'; y ces menester que la razón se apoye sobre estos conocimientos del corazón y del instinto y que fundamente en ellos todo su discurso" (PasCaL, Pensamientos, 282).

8 X. ZuBiru, Naturaleza Historia Dios, Madrid, Alianza, 1987 (9.a ed.).

9 Carta a Ilundáin del 24-5-1899, publicada por Hernán BENfTEZ en El drama religioso de Unamuno, Buenos Aires, 1949, pág. 297.

10 J. Ortega y GaSSET, Obras Completas, IX, pág. 74. 
nuevo "horizonte" para la filosofía, en el que el estudio de los estratos más profundos de la razón desvela una nueva forma de entender la realidad y de estar inteligentemente en ella; y en el que, a la vez, se alumbra una nueva metafisica a la altura del creciente conocimiento científico, del arriesgado poder de la tecnologías y del abismo vital a que nos expone la experiencia trágica y nihilista.

La filosofía no es eterna, tiene «su tiempo», pues es una "posibilidad histórica", una manera de afrontar intelectualmente la vida, que confía en "el poder de la razón", pero que -como advertía Ortega- puede dejar paso a otras maneras postfilosóficas, si se resquebraja la "fe" en la razón que le sirve de sustento. $Y$ es posible que se haya "volatilizado» la confianza en la razón tradicional y, sobre todo, en la moderna, produciendo una crisis intelectual de largo alcance. Tal vez por eso sea tan difícil seguir pensando hoy en día filosóficamente, cuando las urgencias nos arrastran y el interés está volcado en lo inmediato.

Zubiri fue muy consciente de que "para entender una filosofía hay que descubrir su horizonte", caracterizando el nuestro resumidamente por haberse quedado "sin mundo, sin Dios y sin sí mismo" y describiéndolo así: "A solas con su pasar, sin más apoyo que lo que fue, el hombre actual huye de su propio vacío (...) exprime las maravillosas posibilidades técnicas del universo, marcha veloz a la solución de los urgentes problemas cotidianos. Huye de sí mismo, hace trancurrir su vida sobre la superficie de sí mismo. Renuncia a adoptar actitudes radicales y últimas (...) la existencia del hombre actual es constitutivamente centrífuga y penúltima» ${ }^{11}$.

Esta experiencia de abismo que hoy nos invade constituye, a mi juicio, el trasunto de la sospecha de que en el fondo todo es contingente y caótico, que tan sólo contamos con un orden funcional y convencional, y que carecemos de arraigo en la realidad.

De entre las diversas consecuencias de esta situación quisiera destacar dos: 1. a) la de reducir el conocimiento de la realidad al de las ciencias positivas (cientificismo) y poner la organización del mundo (natural y social) en manos del poder de las innovadoras tecnologías (tecnocratismo); y 2.a) la de renunciar a la dimensión metafísica de la filosofía, es decir, aceptar con resignación el advenimiento de una era "postmetafísica".

11 X. Zubiri, Naturaleza Historia Dios, Madrid, Alianza, 1987, 9 ed., págs. 56-57. 
Sin embargo, el hálito de la filosofía primera (a la que puede denominarse también metafísica) sigue presente en nuestros días, no sólo a través de los giros "pragmático" $\mathrm{y}$ "bermenéuticon en su versión transcendental, sino también en virtud de la hermenéutica genealógica de Nietzsche y en la radicalización de la analítica noológica, es decir, tanto por vía de reflexión trascendental como por vía de inmersión en la realidad ${ }^{12}$. Nos ocuparemos, pues, de ello a continuación.

\section{Hermenéutica y Pragmática transcendentales}

Las expresiones "hermenéutica transcendental» $\mathrm{y}$ "pragmática transcendental" caracterizan aspectos decisivos de uno de los programas filosóficos más fructíferos de la segunda mitad del siglo XX, a saber, el programa apeliano de transformación de la filosofia transcendental kantiana, mediante la incorporación del giro fenomenológico-hermenéutico contemporáneo, especialmente el de orientación heideggeriana y gadameriana, la pragmática lingüística (especialmente a partir del segundo Wittgenstein) y el pragmaticismo de Ch. $S$. Peirce.

Los primeros trabajos de Apel en los años cincuenta son de corte hermenéutico, como la tesis de doctorado: "Ser-abi y conocimiento: una interpretación gnoseológica de la filosofia de Martin Heideggen ${ }^{13}$. A partir de entonces se entrelazan en la filosofía de Apel varios enfoques que se irán perfilando y completando con el tiempo: una peculiar profundización hermenéutico-lingüistica de la filosofía de Heidegger y una aproximación a la filosofia del lenguaje que, si bien originariamente es de orientación humboldtiana, se reconduce más tarde hacia la filosofía analitico-lingüística, especialmente en la versión determinada por el giro pragmático del segundo Wittgenstein.

A la hermenéutica de la facticidad de Heidegger y Gadamer añade Apel una serie de elementos críticos y dialécticos, a fin de superar el logos meramente facticista, desvelando las pretensiones universales de validez y sin abandonar el

12 No puedo ocuparme en esta ocasión del actual giro "práctico-aplicado" (vid. al respecto J. ConiLl, "Hermenéutica y filosofía práctica», en Debats, n. 67 (otoño 1999), págs. 59-67).

13 Dasein und Erkennen. Eine erkenntnistheoretische Interpretation der Philosophie $M$. Heideggers, Bonn, 1950. 
problema de la fundamentación o justificación racional, es decir, manteniendo las exigencias propias de una razón crítica dentro del marco de una «semiótica trascendental", entendida como nueva "prima philosophias ${ }^{14}$. El proyecto de esta nueva filosofía primera mantiene la pretensión de lograr una fundamentación filosófica, consistente en reconstruir los presupuestos necesarios e irrebasables de toda argumentación: aquéllos que no podemos negar sin incurrir en contradicción pragmática, ni podemos intentar demostrar sin caer en petitio principii. Es a este tipo de elementos a los que se llama "trascendentales».

Aunque no es fácil hallar una estructuración bien sistematizada de la propuesta filosófica de Apel, éste indica en alguna ocasión que tiene dos partes, la Hermenéutica trascendental y la Pragmática trascendental ${ }^{15}$. La ausencia de una delimitación nítida de los contenidos correspondientes a cada una se debe tal vez a que su procedimiento habitual de pensar y exponer está marcado por sus interlocutores; pero también a que el acercamiento entre la hermenéutica y el análisis lingüístico es ineludible, cuando no se rehuye el tratamiento de la dimensión pragmática del lenguaje. Tanto mediante el método fenomenológico-hermenéutico como con el analítico-lingüístico puede superarse la separación tradicional entre las dimensiones semántica y pragmática.

En efecto, en ambos casos puede tematizarse el lenguaje como condición de posibilidad y validez intersubjetiva, y, por tanto, reintroducirse el rol transformado del sujeto trascendental. Pues las versiones apelianas de la hermenéutica y de la pragmática van más allá del factualismo del sentido, debido a su pretensión de universalidad. Prestar atención a la vitalidad del lenguaje no implica someterse a la mera facticidad, sino reivindicar también el universalismo trascendental. Es decir, conjugar el momento de la participación y el de la distancia critica, porque desde uno mismo se puede ir más allá de sí mismo, dando ocasión al cuestionamiento reflexivo, tal como expresa la noción de

14 Vid. K. O. APEL, "Transzendentale Semiotik und die Paradigmen der Prima Philosophia», E. BÜLOw y P. SCHMITTER (Hrsg.), Integrale Linguistik, Amsterdam, J. Benjamins, 1979, págs. 101-138; J. Conill, "La semiótica trascendental como filosofía primera en K. O. Apel», en Estudios Filośficos, 91 (1983), págs. 493-516; El crepuisculo de la metafisica, Barcelona, Anthropos, 1988, cap. 12; A. CORTINA Y J. CONILL, "Pragmática trascendental", en M. DASCAL (ed.), Filosofia del lenguaje II. Pragmática, Trotta, Madrid, 1999, págs. 137-166.

15 "Transzendentale Semiotik und die Paradigmen der Prima Philosophia», E. BuLow y P. SCHMITTER (Hrsg.), Integrale Linguistik, Amsterdam, J. Benjamins, 1979, págs. 101-138; "¿Cientificismo o hermenéutica trascendental?" (en Transformación de la filosofia, II, 169 ss.). 
"comunidad ideal de comunicación", que tiene entre otras la virtud de abrir un horizonte de intersubjetividad universal.

Lo curioso es que, a pesar de haber aceptado expresamente la posibilidad y necesidad de una "Filosofía Primera", Apel rechaza la conveniencia de la metafísica ${ }^{16}$. Esto podría deberse a la moda convertida ya en tópico en algunos círculos de la filosofía contemporánea que caracterizan nuestra época sin más como "postmetafísica". Pero también puede deberse a alguna que otra confusión. A mi juicio, Apel malentiende el término "metafísica», cuando lo separa tajantemente del uso del término "filosofía primera", ya que en la historia de la filosofía se han asimilado ambos, de tal manera que bien podría llamarse "metafísica» a lo que Apel prefiere denominar "filosofía primera". Sería una cuestión de nombres; pues, si vamos al contenido, lo decisivo de la filosofía primera o de la metafísica consiste en rebasar el nivel de las ciencias particulares y alcanzar el nivel transcendental por el método que sea. En cualquier caso, la filosofia primera o la metafísica sería aquella modalidad de pensamiento que es capaz de alcanzar la transcendentalidad (en la versión que sea).

Por eso, ya hace tiempo, defendí que la filosofía de Apel tenía rasgos y pretensiones que podían ser calificados de metafísicos, aunque fuera en un sentido transformado. Lo cual se debe a que hay ciertas características en su filosofía que revelan una modalidad de pensamiento de un determinado calibre ${ }^{17}$. Y lo mismo debe decirse del pensamiento de Habermas, cuando sigue pretendiendo rescatar la "sustancia normativa de las tradiciones religiosas" (y de lo que él denomina metafísica) manteniendo la uperspectiva del mundo como un todo" y con ello la "universalidad" e incluso la "trascendencia desde dentro", ya que de este modo está conservando características tradicionales del pensamiento metafísico (totalidad, universalidad y trascendencia inmanente), por mucho que se empeñe en aclarar que su pretensión es hacerlo «en condiciones posmetafísicas» ${ }^{18}$. Una vez más, lo importante no es tanto fijarse en lo que dice

16 K. O. APEL, "Transzendentale Semiotik und die Paradigmen der prima philosophia», en E. von BÜLOw y P. SCHMTTTER (eds.), Integrale Linguistik, Amsterdam, 1979, págs. 101-138; "Kann es in der Gegenwart ein postmetaphysisches Paradigma der Erten Philosophie geben?", en H. SCHNADELBACH y otros (eds.), Philosophie der Gegenwart-Gegenwart der Philosophie, Hamburg, Junius, 1993, págs. 41-70.

17 Por ejemplo: transcendentalidad, fundamentación última y evidencias paradigmáticas, orden teleológico y lógico-moral, momento de incondicionalidad, etc. (vid. J. CONILL, El crepúsculo de la metafisica, Barcelona, Anthropos, 1988, cap. 12: "Metafísica de la comunicación»).

18 J. HABERMAS, La inclusión del otro, Barcelona, Paidós, 1999. 
sino en lo que hace. Pues, a pesar de los pesares, lo decisivo no es cambiar el nombre publicitario, sino descubrir las características del nivel filosófico en el que se mueve la reflexión.

En definitiva, en los sedicentes pensamientos posmetafísicos hay mucha más criptometafisica de la que se reconoce. Y esto vale no sólo para Apel y Habermas, sino para otros casos, que alardeando de una especie de utopía posmetafísica exhiben ${ }^{19}$, sin embargo, los rasgos y pretensiones de la metafísica, aunque con el inconveniente de hacerlo de una manera renovadamente acrítica. A mi juicio, esta incapacidad para desembarazarse de la metafísica es un claro síntoma de la necesidad que tiene el pensamiento de contar con ese nivel de reflexión. Es más, una revisión en profundidad de lo que ha ocurrido a través de los procesos de modernización nos muestra que hemos estado reprimiendo aspectos que perviven en los entresijos de la vida y en algunas formas de reflexión. Pues tal vez sea posible reconstruir una metafísica con principios y valores propios, capaces de orientar nuestra vida, más allá del enfoque -en el fondo naturalista y positivista - de la «era epistemológica», que está asfixiando nuestras vidas ${ }^{20}$.

A este propósito de superar el enfoque epistemológico debe contribuir la versatilidad de la reflexión transcendental kantiana, en la medida en que se ha ido descubriendo el nivel trascendental en diversos medios (por ejemplo, en el linguístico y argumentativo) ${ }^{21}$ y se desvelan (desenmascaran) los presupuestos antropológicos y axiológicos que subyacen al prevalente enfoque epistemológico moderno y contemporáneo ${ }^{22}$. Por ejemplo, mediante la indagación de las innegables condiciones del conocimiento y de la experiencia, tal como han llevado a cabo los pioneros estudios de $\mathrm{K}$. O. Apel sobre la versión transcendental de las aportaciones de Heidegger, Wittgenstein y Peirce en sus propuestas de "Pragmática trascendental», "Hermenéutica trascendental» y "Semiótica trascendental», e incluso mediante el aprovechamiento de la fenomenología y antropología contemporánea en su "Gnoseoantropología».

19 J. ConiLl, El crepúsculo de la metafisica, cap. 13: "Postmetafísica como utopía?".

20 Vid., por ejemplo, Ch. TAYLOR, Las fuentes del yo (Barcelona, Paidós, 1996) y Argumentos filosóficos (Barcelona, Paidós, 1997).

21 Vid. K. O. APEL, La transformación de la filosofia, Madrid, Taurus, 1985, 2 vols.; A. CORTINA, Razón comunicativa y responsabilidad solidaria, Salamanca, Sígueme, 1985; J. CONILL, El crepúsculo de la metafisica, Barcelona, Anthropos, 1988, cap. 12; y el n. ${ }^{\circ} 183$ (1999) de la revista Anthropos, monográfico dedicado a K. O. Apel.

22 Vid. J. ConiLl, El enigma del animal fantástico, Madrid, Tecnos, 1991. 
No obstante, a la hora de decidir acerca de qué significa verdaderamente la superación de la epistemología, nos encontramos con una cuestión todavía irresuelta: la confrontación entre la posición nietzscheana y la de los presuntos "defensores de la razón crítica». De ahí que, a mi juicio, estas reflexiones exijan, entre otras cosas, por lo menos, la siguiente: descifrar lo que significa el giro hermenéutico de la filosofía a partir de Nietzsche. Y en este contexto rebrota el sentido innovador que tienen las propuestas orteguiana y zubiriana de una nueva "metafísica», en la medida en que promovieronn un proyecto filosófico que supera el criticismo subjetivista e idealista, propio del enfoque epistemológico ${ }^{23}$.

\section{El giro hermenéutico nietzscheano}

Una auténtica revisión de lo que significa el "giro hermenéutico" exige incluir dentro de su órbita el pensamiento nietzscheano, uno de cuyos grandes méritos consiste, a mi juicio, en haber transformado el criticismo kantiano en hermenéutica genealógica ${ }^{24}$. Precisamente en Nietzsche encontramos el laboratorio mental en el que tuvo lugar un proceso de transformación semejante y, por tanto, en el que aprendemos a percibir el complejo tejido vital de lo que significa la "pugna" entre la experiencia trágico-nihilista y la razón crítica, de tal modo que su interconexión podría comprenderse como una peculiar hermenéutica crítica en clave genealógica.

Y el hecho de que la versión nietzscheana de la hermenéutica genealógica tenga que confrontarse con otras propuestas de hermenéutica como las de Heidegger, Gadamer, Apel y Habermas, Ricoeur, etc., constituye un modo de incorporar el pensamiento nietzscheano al debate racional contemporáneo, más allá del uso panfletario, irracional y extravagante de sus escritos, del que sólo resulta una actitud de ficticia —inmunizada - superioridad, que niega e imposibilita la discusión racional ${ }^{25}$.

23 Cfr. J. ConiLL, "La transformación de la fenomenología en Ortega y Zubiri: La postmodernidad metafísican, en J. SAN MARTIN (ed.), Ortega y la Fenomenologia, Madrid, UNED, 1992, 297-312.

24 Vid. J. CONiLl, El poder de la mentira. Nietzsche y la politica de la transvaloración, Madrid, Tecnos, 1997.

${ }_{25}$ Un síntoma de su relegación del debate racional es que HaBERMAS en el capítulo $1 .^{\circ}$ de La inclusión del otro, titulado "Una consideración genealógica acerca del contenido cognitivo de la moral", ni siquiera menciona a Nietzsche y su genealogía. 
La hermenéutica es la modalidad filosófica más propia de nuestra situación actual. Si en otros momentos fueron preponderantes los marxismos, el positivismo lógico, los existencialismos, las filosofías analítico-lingüísticas, el "racionalismo crítico" y la teoría de sistemas, hoy en día, con un nombre u otro, las diversas filosofías se han acercado cada vez más a una actitud hermenéutica. Se ha ido pasando de unas filosofías centradas en el predominio de la razón epistemologizada a unas filosofías que son cada vez más conscientes del carácter decisivo de la experiencia, incluso para la constitución de la propia razón.

Pues lo primero que hay que resaltar es el carácter experiencial del pensamiento mismo, que implica destacar lo «impuro" de la razón. Más allá de la estructura lógica hay otras necesidades, otros impulsos e instintos, que son los que rigen realmente la vida humana. La genealogía nos ayuda a entender mejor (con más perspectivas) cómo comprendemos realmente, el "acontecer" que hay en todo "comprender», es decir, la experiencia real.

Una experiencia que está cargada de componentes vitales y que la hermenéutica genealógica de Nietzsche desentraña a partir del instinto formador de metáforas ${ }^{26}$. Una experiencia que nos sumerge siempre en una maraña de ficciones, perspectivas e interpretaciones, de la que no podemos desembarazarnos y con la que inevitablemente configuramos (desfiguramos tropológicamente) todos los ingredientes de nuestra existencia. Pues antes de haber pensado (gedacht) ya hemos figurado mediante tropos originarios, ya hemos poetizado (gedichtet), como repite incansable Nietzsche, apuntando al «orto" de su filosofía ${ }^{27}$. Una experiencia cuyo componente más radical es el sufrimiento - iy no un acto puro!-, que nos hace descender a los infiernos y sentir «las máscaras del demonion ${ }^{28}$.

Una de las consecuencias culturales más importantes que se han producido en virtud de este nuevo enfoque hermenéutico de la filosofía contemporánea son las voces que se han alzado en contra de la razón fundamentadora y la extensión de un sentir nihilista, sólo resuelto en cada contexto por las exigencias pragmáticas, como si nos hubiéramos convertido en nihilistas por dentro

26 F. NIETZSCHE, Verdad y mentira en sentido extramoral Madrid, Tecnos.

27 Vid. J. CoNILL, El poder de la mentira, cap. 6: «Pensar y poetizar».

28 Ibid., cap. 8.": «Las "máscaras del demonio": ¿interpretación o transvaloración?". 
(en el orden de las convicciones) y en pragmáticos por fuera (en el orden de las resoluciones) ${ }^{29}$.

Sin embargo, el giro hermenéutico de la filosofía contemporánea no tiene por qué aceptar que el camino de la experiencia conduce irremediablemente al nihilismo y al pragmatismo. Antes bien, una tarea de la filosofía actual consiste en aceptar el primado de la experiencia, pero sin caer en sus posibles consecuencias nihilistas y ciegamente prgmáticas. Es más, un análisis hermenéutico de la experiencia puede contribuir a configurar una critica de la razón impura, que prosiga la crítica de la razón - como tarea permanente de la filosofía-, arrancando del espesor de la experiencia vital y sin regirse por la lógica o por la metodología. Porque no nos encontramos ya siempre sólo, ni prioritariamente, en la razón reflexivo-formal, o en diálogo o en la argumentación, sino que estamos ya siempre ỳ primordialmente en la experiencia.

Así que, si hay que hacer frente a la autodestrucción nihilista y pragmatista-contextualista de la razón, es decir, a la denominada "crítica total de la razón" ${ }^{30}$, a la vez hay que ser conscientes del riesgo que se corre entonces de supeditarse de nuevo a la coerción epistemológica del metodologismo moderno y recaer en un "cartesianismo epistemológico". Ahora bien, entre ambos peligros hay una tercera posibilidad, la que media logos y experiencia en el concepto de una "razón experienciab) ${ }^{31}$. Es ésta una fórmula que, contando indudablemente con precedentes clásicos antiguos y modernos, prosiguen ciertas filosofías contemporáneas y de modo especial la tradición de la filosofía española desde la Generación del 98 (por ejemplo, en el "sentimiento trágico" de Unamuno y en el "pensamiento poético" de A. Machado) hasta la "razón vital" de Ortega, la "razón poética» de Zambrano y la "razón sentiente» de Zubiri, con sus valiosas prolongaciones antropológicas y metafísicas en Pedro Laín y Julián Marías.

29 G. Amengual, Presencia elusiva, Madrid, PPC, 1997; J. Conill, El enigma del animal fantástico, Tecnos, Madrid, 1991.

30 K. O. APEL, «Die Herausforderung der totalen Vernunftkritik und das Programm einer philosphischen Theorie der Rationalitätstypen", Concordia, 11 (1987), 2-23.

31 Vid. J. Conill, El enigma del animal fantástico, Tecnos, Madrid, 1991, parte II: "Hermenéutica crítica de la razón experiencial»; "La verdad de la razón experiencial», en J. A. Nicolás y M.a J. FrAPOLli (eds.), Verdad y experiencia, Granada, Comares, 1998, págs. 181-197. 


\section{Pugna de analíticas}

El giro hermenéutico sirve también para volver a fomentar un impulso siempre latente a lo largo de los siglos en favor del modo de pensar experiencial (método physikôs transformado). Tanto la filosofía de Ortega como la de Heidegger y Gadamer, con sus respectivas modalidades hermenéuticas (de la vida y del Dasein), van por la vía experiencial del pensamiento como forma más "originaria» del pensar (más allá del epistemologicismo) ${ }^{32}$. E igualmente Zubiri nos recuerda que "toda filosofía tiene a su base, como supuesto suyo, una cierta experiencia). "La filosofía no nace de sí misma", sino de la experiencia ${ }^{33}$.

Así pues, aunque una parte de la hermenéutica contemporánea haya entendido que su "destino" es el nihilismo (completado con el pragmatismo), otras modalidades de hermenéutica ofrecen analíticas de la experiencia reah que permiten rebasar los límites de la filosofía formal de la auto-reflexión ${ }^{34}$, al revelar que la experiencia hermenéutica está entrañada de historia, tradición, lenguaje, vida personal, y que, en el fondo, con terminología de Gadamer, está sometida al «poder de la historia efectual». Pero tanto Gadamer como la mayor parte de la hermenéutica olvidan o relegan el momento de realidad ínsito en la experiencia. Es éste un aspecto en el que insistieron las analíticas de Ortega y Zubiri, al indagar hasta el nivel de la "realidad primordial».

La contribución de la filosofía española en este punto es sumamente significativa, porque sólo teniendo en cuenta ese nivel de la realidad radical se podrá ir más allá del peliagudo problema que plantea el «conflicto de las interpretaciones", en el que desemboca la actitud hermenéutica contemporánea, mediante una explícita o implícita pugna de analiticas. Pues, en efecto, la mayoría de las filosofias contemporáneas se sustentan en alguna que otra "analítica» (lingǘrstica, fenomenológica, existencial, noológica...); incluso cuando pretenden alcanzar el nivel metafísico.

Un ejemplo muy característico en el seno de la tradición española fue la propuesta lainiana de una nueva "analítica de la existencia», diferente de la

32 J. CONILl, «Concepciones de la experiencia», Diálogo filosofico, 41 (1998), págs. 148-170.

33 X. ZUBIR, Naturaleza Historia Dios, pág. 153.

34 H. G. GadAmer, Verdad y método, Salamanca, Sígueme, 1977; J. Conill, "Tras la hermenéutica trascendental», en Anthropos, n. 183 (1999), págs. 51-55. 
heideggeriana de Ser y tiempo y cuyo punto de partida no era ya el modo de ser de la pregunta, sino el modo de ser de la creencia. Laín logró un análisis del fenómeno de la espera, tomado como orientación originaria y vislumbró que podría hablarse del "temple de la espera", al cual pertenecerían como formas derivadas la esperanza y la desesperanza. En este estudio Laín afronta el problema de la realidad biológica de la espera, destacando «el decisivo papel del cuerpo en la actividad de esperarm ${ }^{35}$. Se trata de un enfoque diferente al heideggeriano, que está fundado en los análisis antropológicos de X. Zubiri (expuestos en sus cursos de los años cincuenta), que han sido completados con los análisis noológicos (publicados en los años ochenta) ${ }^{36}$.

Pero también otras concepciones filosóficas se apoyan en analíticas, hasta cuando se declaran en franca oposición a tal enfoque, pues de hecho sus formulaciones están supeditadas a determinados análisis de lo que consideran primordial en la existencia humana. Por ejemplo, esto es lo que le ocurre hasta al «Racionalismo crítico», como puede apreciarse en la hermenéutica economicista que practica Hans Albert, que da como resultado, a mi juicio, el análisis de un Dasein no ontológico sino primordialmente económico ${ }^{37}$.

La aportación de las analíticas de la experiencia es ineludible, si no queremos dejar relegado en el olvido precisamente el trasfondo experiencial que está vivificando la razón. Y una reflexión acerca de esta pugna de analíticas de la experiencia es crucial para evaluar las diversas interpretaciones de la vida humana y los proyectos de las nuevas metafísicas, así como para orientar la acción y la organización de nuestras sociedades.

Pensando, pues, "con Gadamer contra Gadamer" y «con Apel contra Apel», creo que se pueden proseguir tanto sus hermenéuticas lingüísticas (la versión ontológica de Gadamer y la pragmático-transcendental de Apel) como la "antropología del conocimiento" de Apel en forma de una "hermenéutica

35 P. LAN , La espera y la esperanza, Madrid, Alianza, 1984 (2.a ed.); Descargo de conciencia, Madrid, Alianza, 1989; D. Gracia, "Pensar la esperanza en el horizonte de la posmodernidad", Revista de filosofia, 2." serie, VIII, enero-junio, 1985, 113-148.

36 X. ZubIRI, Inteligencia sentiente, Madrid, Alianza/Sociedad de Estudios y Publicaciones, 1980; Inteligencia y logos, Madrid, Alianza/Sociedad de Estudios y Publicaciones, 1982.

37 Vid. H. AlBERT, Traktat über rationale Praxis, Tübingen, Mohr, 1978; Kritische Vernunft und menschliche Praxis, Stuttgart, Reclam, 1977; J. CoNILL, El enigma del animal fantástico, Tecnos, Madrid, 1991, cap. 3.0; y J. CoNILl, "Hermenéutica y filosofía práctica", en Debats, n. ${ }^{\circ} 67$ (1999), págs. 59-67. 
antropológica de la experiencia», llamando la atención sobre las raíces experienciales de la presunta razón pura formal y su expresión a través de las pretensiones de validez, es decir, poniendo de relieve las estrechas conexiones entre logos y experiencia vital. Esta insistencia en lo experiencial no implica que la hermenéutica retroceda a una ontología prekantiana ${ }^{38}$. Antes bien, el propósito compartido por Gadamer y Apel es plantear una cuestión filosófica, que se refiere a la "totalidad de la experiencia humana del mundo y la praxis vital»: "¿cómo es posible la comprensión?» ${ }^{39}$. Este enfoque hermenéutico, que remite a la experiencia histórica, supera tanto la epistemología como la filosofía de la reflexión, al proponer una "teoría de la experiencia real», en la que la comprensión se entiende como un acontecer experiencial.

Para superar el planteamiento epistemológico podemos, pues, recurrir a la "hermenéutica de la facticidad", en forma de una teoría de la comprensión como "experiencia real", en la que de un modo ineludible e irrebasable experienciamos el ser como tiempo, pero también, a mi juicio, experienciamos la razón como tiempo. La razón necesita tiempo para conformarse y constituirse como tal. Por eso la estructura dinámica de la razón es histórica y la razón no funciona meramente con sentido formal, sino que su fuerza postuladora y regulativa cuenta ya con ciertos contenidos. Y estos contenidos, ínsitos incluso en las pretensiones de validez, sólo son comprensibles en conexión con categorías del "acontecer", propias del mundo histórico de la experiencia.

Así pues, la analítica de la "razón experiencial" revela una conciliación originaria entre tiempo y razón (del lado fáctico y del ideal de la razón), por consiguiente, que no sólo el ser es tiempo, sino también la razón es tiempo, que el tiempo no es enemigo de la razón.

Las analíticas de la experiencia permiten rebasar los límites epistemológicos de la "filosofía de la reflexión". Pues la presunta superioridad de esta modalidad filosófica consiste en su carácter formal, pero a costa de no tocar la realidad, de quedar al margen de la experiencia real. De ahí que debamos profundizar hasta

38 K. O. APEL, «Sinnkonstitution und Geltungsrechtfertigung. Heidegger und das Problem der Transzendentalphilosophie», en Forum für Philosophie BAD HOMBURG (ed.), Martin Heidegger: Innen-und Aussenansichten, Frankfurt, Suhrkamp, 1989, 131-175; Auseinandersetzungen in Erprobung des transzendentalpragmatischen Ansatzes, Frankfurt, Suhrkamp, págs. 505-568.

39 K. O. APEL, La transformación de la filosofia, I, pág. 41. 
las raíces hermenéuticas y pragmáticas de la razón formal-transcendental, y desvelar - allende todos los argumentos reflexivos- el momento de realidad operante en la experiencia real.

Precisamente esta exigencia - latente en la hermenéutica - ha sido satisfecha programáticamente por el análisis noológico de Zubiri ${ }^{40}$. Y en esta dirección se han encarrilado algunos trabajos de Apel, especialmente al reintroducir la evidencia fenoménica referida a la realidad en la teoría discursiva de la verdad sirviéndose de investigaciones fenomenológicas y phaneroscópicas ${ }^{41}$. Algo parecido habría que hacer con respecto a la experiencia moral (prestando atención a los sentimientos, los valores e intereses), en la que se sustenta la razón práctica. Debería proseguirse así la conexión entre la "antroponomía y la antropología pragmática kantianas en el nuevo marco de la hermenéutica antropológica de la razón experiencial ${ }^{42}$, conciliando la facticidad y la idealidad de la razón también en el ámbito práctico.

A mi juicio, esta profundización y ampliación experiencial de la hermenéutica transcendental permite estar en mejores condiciones para entrar en un debate provechoso, tanto con la filosofía latinoamericana de la liberación como con la posición oscilante de Habermas ${ }^{43}$.

En el primer caso, la razón experiencial es más sensible a las situaciones vitales concretas de pobreza, miseria y opresión, en virtud de la experiencia básica de "reconocimiento recíproco», es decir, de una intersubjetividad vital (y no sólo reflexivo-formal), por la que se reconoce a los afectados, a los sujetos sufrientes desde ellos mismos, en su cruda realidad, donde se experimenta - se siente- el poder de lo real, al margen de cualquier interpretación manipuladora. Es precisamente en la "comunidad de vida" y de sufrimiento, en la

40 X. ZUBIRI, Inteligencia sentiente, Madrid, Alianza, 1980.

41 K. O. Apel, Teoría de la verdad y ética del discurso, Barcelona, Paidós, 1991. Vid. J. CONILl, El crepúsculo de la metafisica, Barcelona, Anthropos, 1988, cap. 13; J. A. NICOLÁs, "Teoría de la verdad consenso-evidencial y teoría de la verdad fenomenológico-real», D. BLANCO et alii, Discurso y realidad págs. 144-156; N. SMILG, "Consenso y evidencia como radicales de la verdad", en Anthropos, n. ${ }^{\circ} 83$ (1999), págs. 59-63.

42 Vid. J. CONILL, "Eleuteronomía y antroponomía en la filosofía práctica de Kant", en J. Carvajal (ed.), Moral, Derecho y Politica en Immanuel Kant, Ediciones de la Universidad de Castilla-La Mancha, 1999, págs. 265-284; J. CoNILL, «Hermenéutica antropológica de la razón experiencial», en D. BLANCO et alii, Discurso y verdad, págs. 131-143.

${ }^{43}$ Cfr. J. CONILL, "Tras la hermenéutica trascendental", en revista Anthropos, n. ${ }^{\circ} 183$ (1999), págs. 51-55, especialmente 54-55. 
que ha incidido la ética de la liberación ${ }^{44}$, y a la que aporta valiosas contribuciones filosóficas, tanto la hermenéutica experiencial como el análisis noológico del fondo sentiente — sufriente- del poder de lo real.

Y, en segundo lugar, la perspectiva experiencial de la razón permitiría profundizar el debate entre Apel y Habermas en cualquiera de sus momentos ${ }^{45}$ : (1) la disensión en el seno de la Pragmática frankfurtiana al caracterizarla como "transcendental" (Apel) o como "universal" (Habermas), con el fin de marcar las distancias con respecto al apriorismo ${ }^{46}$; (2) el recurso a la «eticidad del mundo de la vida" para fundamentar la "Teoría crítica" y entender mejor la radicación de las "pretensiones de validez" en él; ( 3 contribuir no "disolver" sino a enriquecer la ética discursiva, ayudando a rebasar el resto de positivismo que late en la propuesta habermasiana del "principio del discurso", que de tan formal y procedimental, quiere ser "neutral», pero entonces acaba siendo vacío ${ }^{47}$. Nuestra perspectiva hace ver que tras el formalismo y el procedimentalismo cabe descubrir un filón experiencial ${ }^{48}$.

\section{Noología: analítica para una metafísica postnietzscheana}

La actitud filosófica con la que Zubiri desarrolla su Noología se asemeja a «lo que a su modo pretendió Husserl con la fenomenología, plantear el problema del saber a un nivel más radical que el de la antigua metafísica y el de la moderna teoría del conocimienton ${ }^{49}$. Esto explica que relevantes novedades de

44 Vid., por ejemplo, E. Dussel (comp.), Debate en torno a la ética del discurso de ApelMéxico/Madrid, Iztapalapa/Siglo XXI, 1994; R. FORNET-BETANCOURT (ed.), Diskursethik oder Befreiungsethik?, Aquisgrán, Augustinus, 1992; y H. SCHELKHORN, Diskurs und Befreiung, Amsterdam, Rodopi, 1997.

45 K. O. APEL, Auseinandersetzungen in Erprobung des transzendentalpragmatischen Ansatzes, Frankfurt, Suhrkamp, 1998, capítulos 11, 12 y 13; vid. A. CoRTina y J. ConiLl, «Pragmática trascendental», en M. DASCAL (ed.), Filosofia del lenguaje II. Pragmática, Trotta/CSIC, Madrid, 1999, págs. 137-166.

46 J. Habermas, "Was heisst Universalpragmatik?", en APEL, Sprachpragmatik und Philosophie, Frankfurt, Suhrkamp, 1976.

47 A. Cortina, Ética sin moral Tecnos, Madrid, 1990.

48 J. Conill, "Teoría de la acción comunicativa como filosofia de la religión", Estudios filosóficos, 128 (1996), 55-73; "Concepciones de la experiencia", Diálogo filosófico, 41 (1998), 148-169.

49 D. GRACIA, Voluntad de verdad, Labor, Barcelona, 1986, pág. 104. 
la filosofía zubiriana se produzcan al hilo de un diálogo (crítico y superador) con la fenomenología; así, por ejemplo, el concepto zubiriano de realidad surge frente al fenomenológico de cosa-sentido ${ }^{50}$. En efecto, al acotar en Inteligencia sentiente el concepto de realidad como formalidad -el "de suyo"-, lo hace primero frente a la realidad "en sí" (como algo independiente de mi percepción), propia del realismo antiguo; pero, sobre todo, frente a la Fenomenología de Husserl y Heidegger ${ }^{51}$.

Habría que añadir que esta vinculación y confrontación con la Fenomenología se detecta en otros conceptos básicos de la filosofía de Zubiri, cuya nueva insistencia analítica intenta superar la reducción de la realidad a sentido, el enfoque todavía predominantemente epistemológico y la intencionalidad de la conciencia. Zubiri "afina" los análisis fenomenológicos de Husserl y los hermenéuticos de Heidegger poniendo de relieve la «actualidazación» de la realidad en la intelección sentiente y su estructura noérgica ${ }^{52}$.

Pero la persistencia de la "inspiración fenomenológica" 53 hasta en los momentos de configuración de su filosofía madura no quiere decir que se confundan Fenomenología y Noología, ya que la Noología es fruto de una transformación radical de la fenomenología. Tan sólo es que responden a una preocupación semejante o a la misma actitud filosófica de "filosofía primera" ${ }^{54}$, por la que ahora se desarrolla un análisis del "carácter impresivo" de la «formalidad de realidad».

Un texto de la época madura de Zubiri puede iluminar y acreditar el sentido del análisis noológico:

"en el rigor de los términos, el residuo de que nos hablan los fenomenólogos es (...) el momento mismo de realidad. El animal carece de este residuon ${ }^{55}$.

50 Ibid., pág. 199.

51 X. ZUBIRI, Inteligencia sentiente, Madrfid, Alianza, 1980, págs. 59-60.

52 Vid. X. ZUBIR, Inteligencia sentiente, Inteligericia y logos, Inteligencia y razón; Sobre el sentimiento y la volición.

53 A. Pintor-Ramos, Realidad y sentido, Salamanca, Publicaciones de la Universidad Pontificia, 1993; Realidad y verdad, Salamanca, Publicaciones de la Universidad Pontificia, 1994; A. FERRAZ, Zubiri: el realismo radical Cincel, Madrid, 1988.

54 D. Gracia, Voluntad de verdad, pág. 113. (Cfr. Inteligencia sentiente, pág. 35).

55 X. ZUBIRI, "Notas sobre la inteligencia humana", Asclepio 18/19 (1967-68), pág. 346. 
La Noología sería el desarrollo pormenorizado del análisis de este residuo fenomenológico ${ }^{56}$ : el momento de realidad dado en la sensibilidad humana. El análisis de este dato no es una construcción teórica sino, según Zubiri, un "prolijo y complicado" análisis del acto de intelección sentiente, es decir, de la impresión de realidad; un análisis que exige una filosofía de la inteligencia (Noología) y una filosofía de la realidad (Metafísica), más fundamental que la ontología de Heidegger y que la filosofía de la vida de Ortega, es decir, que las otras vías por las que se ha intentado superar también la fenomenología de Husserl.

Zubiri ha descubierto un camino que va desde la fenomenología transformada en forma de noología a una nueva metafísica postnietzscheana ${ }^{57}$. Como acertadamente indica Pedro Laín, la filosofía de Zubiri constituye un intento de "superación metafísica de la fenomenología de Husserl», al pasar "de la intuición de esencias a la visión de realidades". A diferencia de Heidegger, Ortega y Zubiri impulsan una nueva línea metafísica desde dos nociones diferentes de realidad, que "son perfectamente conciliables» ${ }^{58}$.

También Diego Gracia considera que la filosofía madura de Zubiri tiene por objeto encontrar una salida al método fenomenológico. Para ello Zubiri traslada la indagación fenomenológica desde la "conciencia" (Husserl), la "vida" (Ortega) y la "comprensión" (Heidegger), a la "aprehensión». Con lo cual, a mi juicio, rebasa la fenomenología de la esencia y la de la existencia (la Analítica hermenéutica), para ofrecer una Analítica noológica del saber de realidad. El tránsito desde la fenomenología de la conciencia y desde la hermenéutica de la existencia a una Analitica de la facticidad (como Noología) no se produce al margen de la inspiración heideggeriana, pero tampoco se renuncia a la radicalidad fundamental de Husserl; por tanto, queda incorporado el nivel de la facticidad (la formalidad de realidad en la aprehensión), pero sin claudicar ante el giro hermenéutico y su derivación desfundamentadora (de inspiración nietzscheana) ${ }^{59}$.

56 Contra este carácter residual se ha expresado de diversas maneras Zubiri, porque ahora el análisis zubiriano de la sensibilidad no la considera algo residual: da sensibilidad no [es] una especie de residuo "hylético" de la conciencia, como dice Husserl, ni un factum brutum, como la llaman Heidegger y Sartre, sino que es un momento intrínseco y formal de la intelección misma».

57 J. ConILL, El crepisculo de la metafisica, Anthropos, Barcelona, 1988; El enigma del animal fantástico, Tecnos, Madrid, 1991; El poder de la mentira, Tecnos, Madrid, 1997.

58 P. LAín, Cuerpo, alma, persona, Barcelona, Círculo de Lectores, 1995, págs. 115-116 y 201-202.

59 Este trabajo se inscribe en el proyecto de investigación «La ética del discurso como núcleo de las éticas aplicadas", financiado por el Ministerio de Educación y Cultura (PB97-1419-CO2-01). 